\title{
A rare cause of abdominal angina
}

\author{
Gian Piero Carboni, ${ }^{1}$ Silvia Visconti, ${ }^{2}$ Sofia Battisti, ${ }^{2}$ Bruno Beomonte Zobel ${ }^{2}$
}

${ }^{1}$ Department of Nuclear Cardiology, Università Campus Bio- Medico, Rome, Italy;

2Department of Radiology, Università Campus Bio-Medico, Rome, Italy

Correspondence to Professor Gian Piero Carboni, g.carboni@unicampus.it

\section{Summary}

The authors report a case of a young male with median arcuate ligament syndrome (MALS). An abnormally low insertion of the median arcuate ligament fibres caused extrinsic compression and stenosis of the coeliac trunk. However, partial dissection of ligament fibres by laparoscopic surgery did not relieve abdominal angina. Multidetector CT confirmed that MALS did not differ from the preoperative scan. The arcuate ligament compressed the coeliac trunk on expiration, thereby eliciting occlusion of the coeliac trunk. Inspiration induced decompression of the ligament with partial release of occlusion of the coeliac trunk. This leads to hypo-perfusion of intestinal organs and abdominal angina. Considering the severe impairment of quality of life, open surgery for decompression of the coeliac trunk with vascular reconstruction is a reasonable option.

\section{BACKGROUND}

Median arcuate ligament syndrome (MALS) is an unusual condition caused by abnormally low insertion of the median arcuate ligament fibres, resulting in compression and luminal narrowing of the coeliac trunk. These fibres connect the right and left crura of the diaphragm and define the anterior margin of the aortic hiatus. The coeliac trunk supplies blood to digestive splanchnic organs through left gastric, common hepatic and splenic arteries. Supply to the intestines includes the coeliac trunk, superior mesenteric artery (SMA) and inferior mesenteric artery (IMA). The coeliac trunk is an essential source of blood because the interconnections with the SMA and IMA are not adequate to sustain sufficient perfusion to splanchnic organs. MALS has been described as a rare disorder. A prevalence of $1.7 \%$ has been reported in a series of 3449 young patients. ${ }^{1}$ A PubMed search carried out to identify articles from 2008 to June 2011 detected only 33 articles. We used the keywords 'median arcuate ligament syndrome', 'coeliac artery compression syndrome' and 'Dunbar's syndrome' in this search.
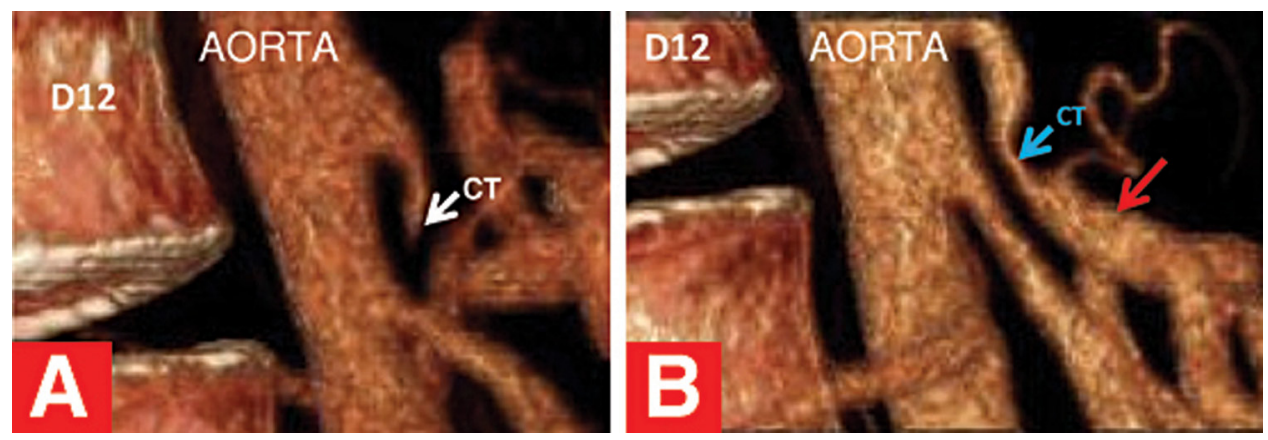

Figure 1 MDCT sagittal three-dimensional volume-rendered images. (A) Occlusion of the coeliac trunk with a 'hook-like' appearance on expiration (white arrow). (B) Release of occlusion of the coeliac trunk during inspiration (blue arrow); poststenosis dilation (red arrow). 


\section{BMJ Case Reports}

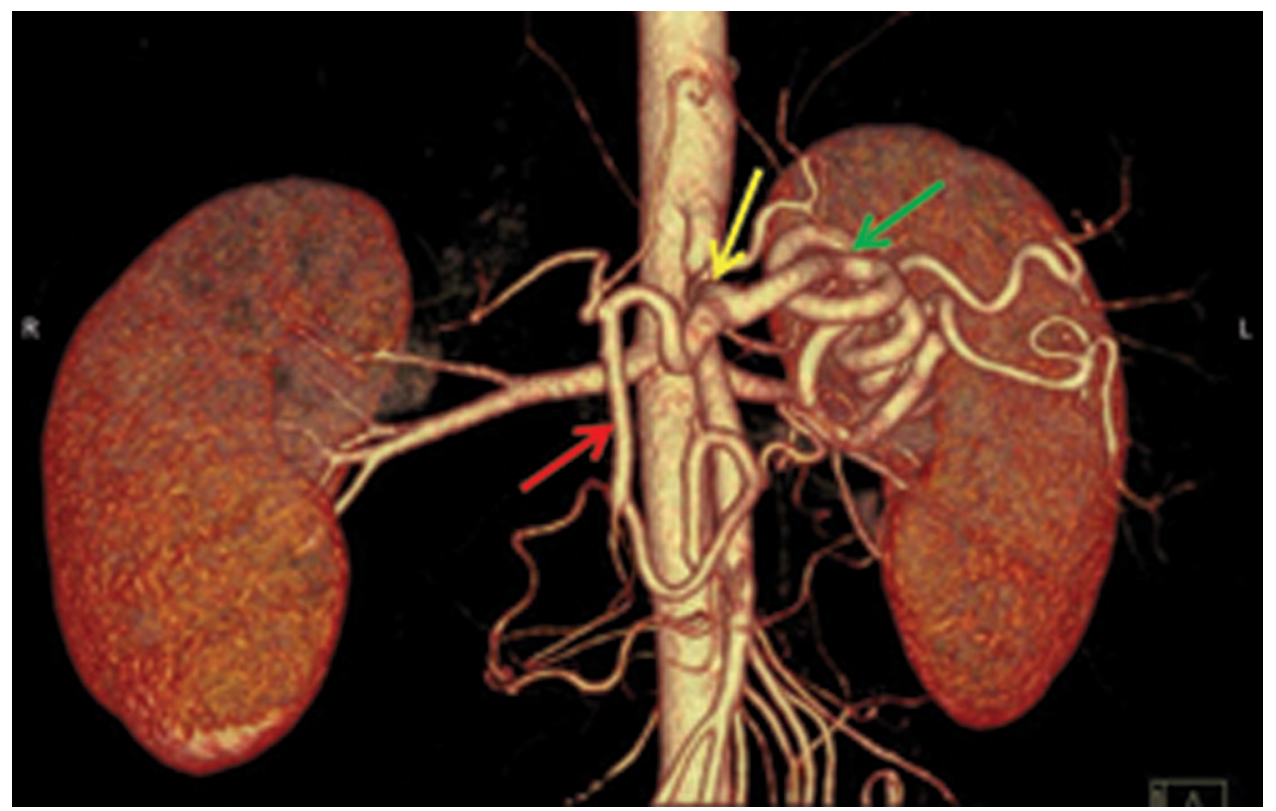

Figure 2 MDCT coronal three-dimensional volume-rendered images. Dilated gastroduodenal artery (red arrow) and splenic artery (green arrow). The gastroduodenal artery is a subdivision of the common hepatic artery and a branch of the coeliac trunk. The splenic artery is a branch of the coeliac trunk (yellow arrow). The calibre of these arteries appears to be increased by more than two-thirds when compared with that of normal patients.

haemodynamic response led to intestinal hypo-perfusion by a 'SMA steal' mechanism.

\section{DIFFERENTIAL DIAGNOSIS}

Chronic intestinal ischaemia is most likely caused by atherosclerosis and less frequently by external compression, fibromuscular dysplasia and vasculitis. ${ }^{2}$ Symptomatic coeliac trunk-dynamic stenosis is an uncommon, potentially underdiagnosed condition of hypo-perfusion of the digestive splanchnic organs. This vascular disorder may involve diverse revascularisation strategies. The use of MDCT during respiration phases is an established method for the diagnosis of MALS.

\section{TREATMENT}

Guidelines for MALS treatment are not available. Therapy remains equivocal.

\section{OUTCOME AND FOLLOW-UP}

During the last few years, this vascular disorder deeply affected the patient's social life. He reduced his number of heavy physical activities, gave up sporting activities and intentionally limited his daily intake of food.

\section{DISCUSSION}

Under resting conditions, visceral multiple connections through the SMA and IMA fulfil intestinal metabolic needs. However, if metabolic demands exceed the supply of blood, intestinal ischaemia occurs with abdominal discomfort, diarrhoea, food avoidance, weight loss or abdominal angina. Laparoscopic surgery has a potential for vascular injury and adjunctive interventions. ${ }^{3}$ Angioplasty or stenting under CT guidance are inadequate if undertaken without release of the extrinsic compression. ${ }^{4}$ Poststenotic dilation and collateral dilated vessels have the potential to evolve into aneurysms with risk of rupture and sudden death. ${ }^{5}$ Taking into consideration the impairment of quality of life and previous unsuccessful laparoscopic surgery, the evaluation of open surgery for decompression of the coeliac trunk with vascular reconstruction is a reasonable option. ${ }^{6}$ In a young patient, the triad of midabdominal bruit, weight loss and undiagnosed gastrointestinal symptoms might suggest MALS. In such cases, the use of a widely available technique such as colour Doppler sonography is the method of choice for initial imaging of this vascular disorder.

\section{Learning points}

- MALS is a rare (but often underdiagnosed) vascular disorder.

- CT undertaken during respiration phases is an established method for the diagnosis of MALS.

- Angioplasty or stenting are inadequate if undertaken without release of the extrinsic compression.

- Colour Doppler sonography is the method of choice for initial imaging in young patients.

Acknowledgements The authors acknowledge Dr Angelo Gorini for his valid technical help.

Competing interests None.

Patient consent Obtained.

\section{REFERENCES}

1. Scholbach T. Celiac artery compression syndrome in children, adolescents, and young adults: clinical and color duplex sonographic features in a series of 59 cases. J Ultrasound Med 2006;25:299-305. 


\section{BMJ Case Reports}

2. Zeller T, Macharzina R. Management of chronic atherosclerotic mesenteric ischemia. VASA 2011;40:99-107.

3. Roseborough GS. Laparoscopic management of celiac artery compression syndrome. J Vasc Surg 2009;50:124-33.

4. Delis KT, Gloviczki P, Altuwaijri M, et al. Median arcuate ligament syndrome: open celiac artery reconstruction and ligament division after endovascular failure. J Vasc Surg 2007;46:799-802.
5. Sugiyama K, Takehara Y. Analysis of five cases of splanchnic artery aneurysm associated with coeliac artery stenosis due to compression by the median arcuate ligament. Clin Radiol 2007;62:688-93.

6. Grotemeyer D, Duran M, Iskandar F, et al. Median arcuate ligament syndrome: vascular surgical therapy and follow-up of 18 patients. Langenbecks Arch Surg 2009;394:1085-92.

This pdf has been created automatically from the final edited text and images.

Copyright 2011 BMJ Publishing Group. All rights reserved. For permission to reuse any of this content visit http://group.bmj.com/group/rights-licensing/permissions.

BMJ Case Report Fellows may re-use this article for personal use and teaching without any further permission.

Please cite this article as follows (you will need to access the article online to obtain the date of publication).

Carboni GP, Visconti S, Battisti S, Beomonte Zobel B. A rare cause of abdominal angina. BMJ Case Reports 2011;10.1136/bcr.08.2011.4572, date of publication

Become a Fellow of BMJ Case Reports today and you can:

- Submit as many cases as you like

- Enjoy fast sympathetic peer review and rapid publication of accepted articles

- Access all the published articles

- Re-use any of the published material for personal use and teaching without further permission

For information on Institutional Fellowships contact consortiasales@bmjgroup.com

Visit casereports.bmj.com for more articles like this and to become a Fellow 